\title{
Financial Prudence of Healthcare Screening Program in Urban Set-up
}

\author{
${ }^{1}$ Madhav M Singh, ${ }^{2}$ Nishu Singh, ${ }^{3}$ Aditya Kumar, , ${ }^{4}$ Saroj K Patnaik, ${ }^{5}$ Ashuthosh Sharma, ${ }^{6}$ Tapas Paul
}

\begin{abstract}
Introduction: Health screening is one of the rapidly growing and accepted practice in healthcare setup across the globe. Public health screening programs are used to control epidemics of infectious disease and to target treatment for numerous chronic diseases.
\end{abstract}

\section{Methods:}

Duration of the study: The study was carried out from November 2018 to January 2019.

Study setting: The study was carried out at Meerut.

Study design: Traditional costing was done, and then a comparison was drawn to estimate the realistic costs incurred towards medical camp.

Results: The cost of screening during the camp was INR 616 per person. With this cost, a large number of disorders were detected in an early stage which has the potential to develop in full-blown disease which may cause more cost to society at large. Hence this study recommends such screening program for families should be carried out on the frequent interval at least annually.

Conclusion: Public health screening programs are used to control disease and to target treatment for acute or chronic diseases. Medical screening programs provide medical as well as socioeconomic benefits. Medical screening is a method for detecting disease or body dysfunction before an individual would normally seek medical care. The fundamental purpose of screening is early diagnosis and treatment of the individual and, thus, it has a clinical focus. Screening tests are generally administered to people who have not yet sought medical care, but at high risk for certain adverse health outcomes. This is a very cost-effective method of preventing the disease at an early stage. The study revealed the screening program is a very effective tool, as shown in this study.

Keywords: Cost-benefit evaluation, Cost-effectiveness, Healthcare, Screening program.

How to cite this article: Singh MM, Singh N, Kumar A, Patnaik SK, Sharma A, Paul T. Financial Prudence of Healthcare

\footnotetext{
${ }^{1}$ Commanding Officer, ${ }^{2,3}$ Medical Officer, ${ }^{4}$ Associate Professor, ${ }^{5} \mathrm{HOD},{ }^{6}$ Dental Officer

Corresponding Author: Saroj K Patnaik, Associate Professor, Department of Hospital Administration, Armed Forces Medical College, Pune, Maharashtra, India, e-mail: patnaik.saroj@ gmail.com
Screening Program in Urban Set-up. Int J Res Foundation Hosp Healthc Adm 2018;6(2):51-56.

\section{Source of support: Nil \\ Conflict of interest: None}

\section{INTRODUCTION}

Health screening is one of the rapidly growing and accepted practice in healthcare set-up across the globe. ${ }^{1}$ Public health screening programs are used to control epidemics of infectious disease and to target treatment for numerous chronic diseases. ${ }^{2}$ Proponents of screening programs stress that in addition to the potential of early disease detection, they also provide the opportunity for screening participants to change unhealthy lifestyles through the so-called lifestyle counseling.

Health screening tests have a great impact on public's health because they involve testing of asymptomatic populations for specific diseases or health conditions. ${ }^{3}$ Medical screening is conducted by the examination of individuals with no signs for the disease to detect those at higher risk of having or developing a disease. Its result in identifying the disease early for better interventions and management of the disease. It divides the people into two categories who are likely to develop and those who are unlikely to develop the disease.

A cost-effectiveness analysis is used when a cost-benefit analysis is not a viable analysis option because you can't place value on the outcome. This method is most commonly used in healthcare when evaluating various treatment plans, health screening program, etc. Providers can assess the cost of a given course of action/program such as physical therapy versus surgery or medical camp. However, it is difficult to predict and value outcomes because patient success and obstacles are all unique and different.

\section{METHODS}

\section{Duration of the Study}

The study was carried out from November 2018 to January 2019.

\section{Study Setting}

The study was carried out at Meerut. 


\section{Study Design}

Traditional costing was done using the existing information, and then a comparison was drawn to estimate the realistic costs incurred towards medical camp.

\begin{tabular}{l}
\hline P1 Cases \\
\hline Focal reversible pulpitis \\
Acute palpitis \\
Chronic pulpitis \\
Chronic hypoplastic pulpitis \\
Periapical abscess \\
Periapical cyst \\
Periapical granuloma \\
\hline Cellulitis \\
Acute necrotizing ulcerative gingivitis \\
Chronic herpetic gingivostomatitis \\
chronic marginal gingivitis \\
Pericoronitis \\
All root stumps/extraction \\
all denture cases \\
\hline P2 Cases \\
Periodontal pocket \\
Tooth attrition abrasion erosion \\
Smooth surface caries \\
Cervical caries \\
\hline P3 Cases \\
Grade 1 calculus \\
Tarter \\
Stains \\
Deposit cases without marked gingivitis and pinpoint cavities \\
\hline
\end{tabular}

\section{Data Collection, Tabulation, and Computation}

The cost information was collected from each department and facilities involved in the medical camp. The health screening was conducted for families (women $>25$ years of age) to ruled out any impending healthcare problem. The following examination was conducted by a doctor and dental officers to check.

- Checking of vital parameters: pulse, BP, temperature, respiratory rate, weight, a sign of anemia

- Any skin disorder, eye checkup, sign for any thyroid disorders

- Dental checkup for all 3 categories ( P1, P2, and P3 ) After screening medical and, dental examination following lab test was conducted:

- Biochemistry (Include)

- Hematology (TLC, DLC)

- Urine RE

- Cholesterol

- Triglyceride

- Uric acid

- Sugar: Fasting and postprandial

- Hemoglobin
After lab result were obtained the data were analyzed using appropriate statistical data and Excel. The cost of manpower, vehicle, lab reagent was calculated as under in Table 1.

The cost of lab reagent taken for medical camp for lab investigation as shown in Table 2.

The total cost is calculated as under Table 3.

The lab results were analyzed as shown in Table 4.

Out of 232 female respondents, following medical abnormalities were detected as shown in Table 5. The results of the screening program were overwhelming. The female population screened were suffering from overweight (19\%), out of which 4 were required under attention to reduce their weight $(>30 \%)$ overweight. These patients were advised diet as well as moderate exercise to start with and follow-up. The skin disorders were mostly related to environment related like dry/cracked skin, eczema, psoriasis, acne, rosacea, ichthyosis, vitiligo, hives, and seborrheic dermatitis.

The female respondents showed clinical features of thyroid disorder while screening was dry, itchy skin, dry, coarse hair, hair loss, weight loss, despite normal eating habits, enlargement of the thyroid gland (goiter), change in menstrual cycles and bulging eyes.

All these patients were referred to a concerned specialist for future treatment. The eye problems were also detected during screening mostly near, and distant vision all of them sent to an ophthalmologist for an opinion.

Out of 232 female respondents, following dental abnormalities were detected as shown in Table 6. The dental abnormalities are common in all ages because of poor dental hygiene and not using appropriate dental products. 4

A large number of respondent were not aware of their blood group. The blood grouping was conducted in the camp. The results are shown in Table 7.

Table 1: Cost of manpower, vehicle per day

\begin{tabular}{lll}
\hline Manpower & Per day salary & Total \\
\hline Medical officer-01 & 4000 & 4000.00 \\
Dental officer-01 & 4000 & 4000.00 \\
Health JCO-01 (paramedic) & 1800 & 1800.00 \\
Health NCO-01 (paramedic) & 1100 & 1100.00 \\
Dental JCO-01 (paramedic) & 1800 & 1800.00 \\
Dental NCO-01 ( Paramedic) & 1600 & 1600.00 \\
LAB NCO-02 ( Paramedic) & $1650+1650$ & 3300.00 \\
BTA NCO-01( Paramedic) & 1600 & 1600.00 \\
Nursing Assistant-01 (paramedic) & 1300 & 1300.00 \\
Ambulance Asst - 03 (paramedic) & $1066+1066$ & 3200.00 \\
& +1066 & \\
Housekeeper-02 & $1300+1300$ & 2600.00 \\
Driver-01 & 1100 & 1100.00 \\
LS Vehicle-01 & $14+3+14$ & 558.00 \\
& $=31 \mathrm{~km} 4 \mathrm{~km} / \mathrm{ltr}$ & \\
& $=7.75 \times 72.00$ &
\end{tabular}

27958.00 
Financial Prudence of Healthcare Screening Program in Urban Set-up

Table 2: Cost of lab reagent per day

\begin{tabular}{|c|c|c|c|c|c|c|c|c|c|c|}
\hline $\begin{array}{l}\text { S. } \\
\text { No. }\end{array}$ & Nomenclature & $A / U$ & Qty & $\begin{array}{l}\text { Supply } \\
\text { rate }\end{array}$ & $\begin{array}{l}\text { Qty } \\
\text { reqd }\end{array}$ & Qty/01 & Qty /100 & $\begin{array}{l}\text { Day } 1 \\
(72)\end{array}$ & $\begin{array}{l}\text { Day } 2 \\
\text { (71) }\end{array}$ & $\begin{array}{l}\text { Day } 3 \\
(99) \\
\end{array}$ \\
\hline 1. & Glucose kit of $400 \mathrm{~mL}$ & Kit & 1 & 370.00 & 2 & 1.95 & 194.74 & 140.2105 & 138.2632 & 192.7895 \\
\hline 2. & Urea kit of $100 \mathrm{~mL}$ & Kit & 1 & 1160.00 & 1 & 12.89 & 1288.89 & 928 & 915.1111 & 1276 \\
\hline 3. & Creatnine kit of $100 \mathrm{~mL}$ & Kit & 1 & 1060.00 & 1 & 11.78 & 1177.78 & 848 & 836.2222 & 1166 \\
\hline 4. & Uric acid kit of $100 \mathrm{~mL}$ & Kit & 1 & 1458.00 & 1 & 16.20 & 1620.00 & 1166.4 & 1150.2 & 1603.8 \\
\hline 5. & Cholesterol kit of $100 \mathrm{~mL}$ & Kit & 1 & 1044.00 & 1 & 11.60 & 1160.00 & 835.2 & 823.6 & 1148.4 \\
\hline 6. & Triglyceride kit of $100 \mathrm{~mL}$ & Kit & 1 & 2310.00 & 1 & 25.67 & 2566.67 & 1848 & 1822.333 & 2541 \\
\hline 7. & HDL cholesterol kit $100 \mathrm{~mL}$ & Kit & 1 & 1230.00 & 1 & 13.67 & 1366.67 & 984 & 970.3333 & 1353 \\
\hline 8. & LDL cholesterol kit $100 \mathrm{~mL}$ & Kit & 1 & 1230.00 & 1 & 13.67 & 1366.67 & 984 & 970.3333 & 1353 \\
\hline 9. & Bilirubin kit of $100 \mathrm{~mL}$ & Kit & 1 & 925.00 & 1 & 10.28 & 1027.78 & 740 & 729.7222 & 1017.5 \\
\hline 10. & Total protein kit of $100 \mathrm{~mL}$ & Kit & 1 & 470.00 & 1 & 5.22 & 522.22 & 376 & 370.7778 & 517 \\
\hline 11. & Albumin kit of $100 \mathrm{~mL}$ & Kit & 1 & 725.00 & 1 & 8.06 & 805.56 & 580 & 571.9444 & 797.5 \\
\hline 12. & SGOT kit of $100 \mathrm{~mL}$ & Kit & 1 & 1210.00 & 1 & 13.44 & 1344.44 & 968 & 954.5556 & 1331 \\
\hline 13. & SGPT kit of $100 \mathrm{~mL}$ & Kit & 1 & 1325.00 & 1 & 14.72 & 1472.22 & 1060 & 1045.278 & 1457.5 \\
\hline 14. & Drabkin's solution. & Ltr & 1 & 210.00 & 5 & 1.05 & 105.00 & 75.6 & 74.55 & 103.95 \\
\hline 15. & Leshmen stain bott of $500 \mathrm{~mL}$ & Bott & 1 & 380.00 & 1 & 0.76 & 76.00 & 54.72 & 53.96 & 75.24 \\
\hline 16. & Glass slide pkt of 50 & Pkt & 1 & 80.00 & 2 & 1.25 & 125.00 & 90 & 88.75 & 123.75 \\
\hline 17. & Anti sera A $10 \mathrm{~mL} / 100$ test & Ml & 1 & 87.00 & 0.1 & 0.87 & 87.00 & 62.64 & 61.77 & 86.13 \\
\hline 18. & Anti sera $B 10 \mathrm{~mL} / 100$ test & $\mathrm{Ml}$ & 1 & 87.00 & 0.1 & 0.87 & 87.00 & 62.64 & 61.77 & 86.13 \\
\hline 19. & Anti sera $O 10 \mathrm{~mL} / 100$ test & Ml & 1 & 87.00 & 0.1 & 0.87 & 87.00 & 62.64 & 61.77 & 86.13 \\
\hline 20. & Anti sera $A B 10 \mathrm{~mL} / 100$ test & $\mathrm{Ml}$ & 1 & 87.00 & 0.1 & 0.87 & 87.00 & 62.64 & 61.77 & 86.13 \\
\hline 21. & Anti sera D $10 \mathrm{~mL} / 100$ test & Ml & 1 & 87.00 & 0.1 & 0.87 & 87.00 & 62.64 & 61.77 & 86.13 \\
\hline 22. & Urostrippkt of 100 & Pkt & 1 & 440.00 & 1 & 4.40 & 440.00 & 316.8 & 312.4 & 435.6 \\
\hline 23. & Urine cotainerpkt of 100 & No & 1 & 7.00 & 1 & 7.00 & 700.00 & 504 & 497 & 693 \\
\hline 24. & Vaccutainer Sterile & No & 1 & 4.80 & 1 & 4.80 & 480.00 & 345.6 & 340.8 & 475.2 \\
\hline 25. & Vaccutainer EDTA & No & 1 & 4.80 & 1 & 4.80 & 480.00 & 345.6 & 340.8 & 475.2 \\
\hline 26. & Vaccutainer sodium fluoride & No & 1 & 4.80 & 2 & 4.80 & 480.00 & 345.6 & 340.8 & 475.2 \\
\hline 27. & Microtips $200-1000$ yl pkt of 500 & No & 1 & 200.00 & 1 & 0.40 & 40.00 & 28.8 & 28.4 & 39.6 \\
\hline 28. & Microtips $0.5-200 \mathrm{yl} \mathrm{pkt}$ of 1000 & No & 1 & 200.00 & 1 & 0.20 & 20.00 & 14.4 & 14.2 & 19.8 \\
\hline 29. & Syringe $5 \mathrm{~mL}$ pkt of 100 & No & 1 & 3.90 & 2 & 7.80 & 780.00 & 561.6 & 553.8 & 772.2 \\
\hline 30. & Sterilium & No & 1 & 390.00 & 1 & 390.00 & 390.00 & 390.00 & 390.00 & 390.00 \\
\hline 31. & Cotton $50 \mathrm{~g}$ & Roll & 1 & 25.00 & 1 & 25.00 & 25.00 & 25.00 & 25.00 & 25.00 \\
\hline 32. & Gloves pkt of 25 & No & 1 & 362.50 & 1 & 14.50 & 14.50 & 14.50 & 14.50 & 14.50 \\
\hline 33. & BMW polythin & No & 1 & 9.00 & 3 & 10.00 & 30.00 & 30.00 & 30.00 & 30.00 \\
\hline
\end{tabular}

Table 3: Total cost of screening camp

\begin{tabular}{llll}
\hline S. No. & Cost Head & Per day cost & Total \\
\hline 1. & Manpower + veh & $27958.00 \times 3$ & 83875 \\
2. & Lab reagent cost $(\mathrm{N}=232)$ & $14913+14712+20333$ & 59058 \\
& & $1,42,932$ \\
\hline & & $1,42,932 / 232=616.08 \mathrm{inr}$ \\
\hline
\end{tabular}

Table 4: Lab investigation

\begin{tabular}{llllll}
\hline \multicolumn{7}{c}{$\begin{array}{l}\text { Total } \\
\text { Number of }\end{array}$} & $\begin{array}{l}\text { Abnormal } \\
\text { tests }\end{array}$ & Test & \% abnormal & $\%$ normal & Remark \\
Test & 3952 & 67 & 1.69 & 98.31 & \\
\hline Biochemistry & 33 & 3.42 & 96.58 & \\
Hematology & 964 & 33 & 2.48 & 97.51 & Abnormal urine RE \\
Urine & 1046 & 26 & 18.53 & 81.46 & High cholesterol $(>200 \mathrm{mg} \%)$ \\
Cholesterol & 232 & 43 & 3.44 & 96.55 & High triglyceride $(>150 \mathrm{mg} \%)$ \\
Triglyceride & 232 & 8 & 3.44 & 96.55 & High uric acid $(>7 \mathrm{mg})$ \\
Uric acid & 232 & 8 & 5.17 & 84.82 & High blood sugar $(\mathrm{F}:>110 \mathrm{mg} / \mathrm{dL} . \mathrm{PP}>140 \mathrm{mg} / \mathrm{dL})$ \\
Blood sugar & 232 & 12 & 14.22 & 85.77 & Anemia $($ Hb $<9$ gm $\%)$ \\
Low & 232 & 33 & & & \\
Hemoglobin & & & 0.86 & 99.13 & High Bilirubin $($ Icterus ++$)$ \\
\hline Bilirubin & 232 & 2 & &
\end{tabular}




\begin{tabular}{ll}
\hline \multicolumn{2}{c}{ Table 5: Medical abnormalities detected } \\
\hline Disease/abnormality detected & Number of cases \\
\hline Skin disorders & 08 \\
Sign of thyroids disorders & 04 \\
Low vision (distant/near) & 26 \\
Overweight (>10 \%) & 46 \\
Anemia (<9 gm \% Hb) & 33 \\
High Blood sugar (F : > 110 mg /dL & 12 \\
PP >140 mg /dL) & \\
Jaundice high bilirubin (Icterus ++$)$ & 2 \\
High uric acid $(>7$ mg) & 8 \\
High cholesterol $(>200 \mathrm{mg} \%)$ & 43 \\
High triglyceride $(>50 \mathrm{mg} \%)$ & 8 \\
UTI & 4 \\
\hline
\end{tabular}

Table 7: Blood grouping result

\begin{tabular}{llll}
\hline Blood group & Positive & Negative & Total \\
\hline $\mathrm{A}$ & 57 & 03 & 60 \\
$\mathrm{~B}$ & 73 & 03 & 76 \\
$\mathrm{AB}$ & 19 & 02 & 21 \\
$\mathrm{O}$ & 72 & 03 & 75 \\
\hline Total & 221 & 11 & 232 \\
\hline
\end{tabular}

The cost of screening during the camp was INR 616 per person. With this cost, a large number of disorders were detected in an early stage which may develop in full-blown disease which may cause more cost to society at large. Hence this study recommends such a screening program for families should be carried out on the frequent interval at least annually.

\section{DISCUSSION}

Screening is commonly used for case finding-identifying a previously unknown or unrecognized clinical condition in apparently healthy or asymptomatic persons and offering treatment to those individuals. Screening might be defined as the active search for a disease (or a pre-disease condition) in patients who are presumed and presume themselves to be healthy. In such a setting, screening is, in general, not able to reduce the likelihood of a certain disease; however, it may reduce its negative consequences. Therefore, screening is a form of secondary prevention.

The cost-benefit evaluation and the cost-effectiveness evaluation are two different tools that we choose to use evaluate business decisions. Both methods are used to comparing the future or impending purchase of new equipment or programs based on their cost and their expected benefits to the company, but one may be more suitable for certain circumstances than the other.

The cost-effectiveness methods are a more appropriate method for any health screening prog. A cost-effectiveness evaluation use to compare is more complex than the costbenefit method because it involves more components.
Table 6: Dental abnormalities found during medical screening CAMPB 4

\begin{tabular}{ll}
\hline & Number of cases \\
Cases & detected \\
\hline P1 cases & 50 \\
Focal reversible pulpitis & 5 \\
Acute palpitis & 4 \\
Chronic pulpitis & 6 \\
Chronic hypoplastic pulpitis & 2 \\
Periapical abscess & 12 \\
Periapical cyst & 2 \\
Periapical granuloma & 1 \\
Cellulitis & 2 \\
Acute necrotizing ulcerative gingivitis & 3 \\
Chronic herpetic gingivostomatitis & 2 \\
Chronic marginal gingivitis & 1 \\
Pericoronitis & 6 \\
All root stumps/extraction & 4 \\
All denture cases & NIL \\
P2 cases & 51 \\
Periodontal pocket & 10 \\
Tooth attrition abrasion erosion & 6 \\
Smooth surface caries & 28 \\
Cervical caries & 6 \\
P3 cases & 77 (Overlap of \\
& diseases) \\
Grade 1 calculus & 28 \\
Tarter & 22 \\
Stains & 22 \\
Deposit cases without marked gingivitis & 61 \\
and pinpoint cavities & \\
Fit cases & 54 \\
\hline &
\end{tabular}

A cost-effective analysis provides more insights into potential success.

Criteria for an effective screening test. ${ }^{5}$ The following criteria need to be met to have an effective screening program:

- Significant societal burden

- Detectable asymptomatic phase

- Accurate screening test

- Acceptable and feasible test

- Effective intervention for those screened positive

- Effective prognostication of those screened positive.

- Cost-effectiveness of the screening program and its availability on a continuing basis

- Presence of safeguards to ensure informed consent and patient confidentiality

\section{Criteria of Wilson and Jungner (Bull World Health Organ, 1968)}

- The conditions sought should be an important health problem.

- There should be an accepted treatment for patients with recognized disease.

- Facilities for diagnosis and treatment should be available. 
- There should be a recognizable latent or early symptomatic stage.

- There should be a suitable test or examination.

- The test should be acceptable to the population.

- The natural history of the condition, including development from latent to declared disease, should be adequately understood.

- There should be an agreed policy on whom to treat as patients.

- The cost of case-findings (including diagnosis and treatment of patients diagnosed) should be economically balanced in relation to possible expenditure on medical care as whole.

- Case-finding should be a continuing process and not a "once and for all" project.

Cost-effectiveness analysis (CEA) is the best decisionmaking tool. It identifies the economically most efficient way to fulfill an objective. CEA of screening prog is used to determine whether a screening intervention is economically efficient, by comparing its costs and effects with costs and effects of all alternatives including doing nothing.

Over-diagnosis and overtreatment is a main concern for many screening tests particularly when evidence either points to net harm or it is insufficient, conflicting or supports only a few magnitudes of net benefit. ${ }^{6}$

Gender bias results in the neglect of female children and selective abortion and excess female mortality in China, India, and other South Asian countries, explaining the "missing" women in population counts. The global burden of disease for 2001 proportionally affects males slightly more than females.

Good maternal health services are one of the keys to strengthen the entire health system. A healthcare facility that is well equipped to provide the most essential obstetric care can also treat accidents, trauma, and other medical emergencies. ${ }^{7}$

Recently, in one of the reports of World Bank (2006) has also reported that chronic and noncommunicable diseases are now main leading causes of death across the globe, amounting for about $60 \%$ of all deaths. ${ }^{8}$

Another recent study conducted in Andhra Pradesh by Joshi et al. ${ }^{9}$ points to similar evidence with regard to the majority of deaths occurring due to non-communicable diseases and injuries. Nevertheless, India is known for gender discrimination in terms of healthcare utilization, food allocation, etc. Studies conducted during the 19thcentury point out females being restricted from seeking healthcare leads to poorer health status. ${ }^{10}$ The India GBD Collaborators ${ }^{11}$ reported that leading cardiovascular diseases-ischaemic heart disease and stroke-are one of the largest contributions to the total mortality in India in 2016 , at $28 \cdot 1 \%$.
National program in India is running in a focal manner where more emphasis on providing secondary care. Screening program is running without the provision of lab reagent due to lack of fund.

\section{CONCLUSION}

Public health screening programs use to control disease and to target treatment for acute or chronic diseases. Medical screening programs provide medical as well as socioeconomic benefits. Medical screening is a method for detecting disease or body dysfunction before an individual would normally seek medical care. If medical screening programs are poorly conceived, organized, or implemented, they may lead to interventions of questionable merit and result may be biased. The fundamental purpose of screening is early diagnosis and treatment of the individual and, thus, it has a clinical focus. Screening tests are generally administered to people who have not yet sought medical care, but at high risk for certain adverse health outcomes. This is a very costeffective method of preventing the disease at an early stage. The study revealed the screening program is a very effective tool, as shown in this study.

\section{REFERENCES}

1. Berk ML, Schur C. Access to care: how much difference does Medicaid make? Health Affairs 1998;17:169-180.

2. Reducing the Odds: Preventing Perinatal Transmission of HIV In The United States. Institute of Medicine (US) Committee on Perinatal Transmission of HIV; National Research Council (US) and Institute of Medicine (US) Board on Children, Youth, and Families; Stoto MA, Almario DA, McCormick MC, editors. Washington (DC): National Academies Press (US); 1999.

3. Calleson DC, Seifer SD, Maurana C. Forces affecting community involvement of AHCs: perspectives of institutional and faculty leaders. Academic Medicine 2002;77(1):72-81.

4. Glick M. The mouth is a mirror of the body. In Closing the Gap, a newsletter.July. Washington, DC: Office of Minority Health, Department of Health and Human Services. 1999.

5. Kopans DB, Monsees B, Smith R, Feig S. Ten criteria for effective screening. AJR. American journal of roentgenology. 2002;178(2):508-510.

6. US Preventive Services Task Force. Screening for prostate cancer: Recommendations and rationale. Am Fam Physician. 2003;67:787-792.

7. Buvinić M, Medici A, Fernández E, et al. Gender Differentials in Health. In: Jamison DT, Breman JG, Measham AR, et al., editors. Disease Control Priorities in Developing Countries.2nd edition. Washington (DC): The International Bank for Reconstruction and Development / The World Bank; 2006. Chapter 10. Available from: https://www.ncbi.nlm.nih. gov/books/NBK11729/ Co-published by Oxford University Press, New York.

8. World Bank. Global Burden of Disease and Risk Factors. New York: Oxford University Press. 2006.

9. Joshi R, Cardona M, Iyengar S, Sukumar A, Raju CR, Raju $\mathrm{KR}$, et al. Chronic diseases now a leading cause of death in rural India-mortality data from the Andhra Pradesh Rural 
Health Initiative. International journal of epidemiology. 2006;35(6):1522-1529.

10. Gupta MD. Selective discrimination against female children in rural Punjab, India. Population and development review. 1987;13(1):77-100.
11. Prabhakaran D, Jeemon P, Sharma M, Roth GA, Johnson $\mathrm{C}$, Harikrishnan $\mathrm{S}$, et al. The changing patterns of cardiovascular diseases and their risk factors in the states of India: the Global Burden of Disease Study 1990-2016. The Lancet Global Health. 2018;6(12):e1339-1351. 